\title{
Teaching electromagnetism using interactive-invention instructional strategy and the learning outcome of secondary school students
}

\author{
Edidiong Enyeneokpon Ukoh* \\ University of Ibadan. Oduduwa Road, 200132, Ibadan, Nigeria \\ nsiadiaha@yahoo.com \\ * Corresponding Author.
}

Received: 15 July 2021; Revised: 8 August 2021; Accepted: 24 November 2021

\begin{abstract}
Electromagnetism is an important aspect of physics in Nigerian secondary school curriculum and has been identified as one of the difficult topics to learn by the students. There seem to be very little research on how to make the learning of electromagnetism easy and enjoyable. Therefore, this study determined the effect of teaching electromagnetism using interactive-invention instructional strategy on senior secondary II (SSII) physics students learning outcome. Pretest posttest control group quasi-experimental research design was employed with 125 SSII students from three randomly selected schools. Intact classes were used and two experimental groups were taught using interactive-invention instructional strategy: group I students worked individually and group II students worked in groups of five and control group was taught conventionally. Two research instruments were used to gather data for the study, namely physics achievement worksheets and in-class interview guide. Students in the experimental groups demonstrated better understanding of the concepts more than those in the control group. In-class interview was carried out at the end of the treatment and all the students in the experimental groups reported that they enjoyed learning the concepts because they had opportunity for hands-on activities and they will prefer that electromagnetic concepts be taught using instructional materials they could manipulate to observe what happens by themselves. It was recommended that teachers use this strategy where hands-on activity-based was emphasized to enhance easy learning of electromagnetism.

Keywords: learning electromagnetism, interactive-invention instructional strategy, handson activity-based, learning outcomes in physics
\end{abstract}

How to Cite: Ukoh, E. E. (2021). Teaching electromagnetism using interactive-invention instructional strategy and the learning outcome of secondary school students. Momentum: Physics Education Journal, 6(1), 10-18. https://doi.org/10.21067/mpej.v6i1.5463

\section{Introduction}

Physics studies the natural phenomena experimentally and theoretically, through complicated concepts and mathematical equations connecting those concepts. Physics Education Research (PER), on the other hand, aims to teach those concepts, related phenomena and mathematical equations with an enhanced comprehension. Physics educators, around the world, try to ease and teach intricate and so believed abstract concepts and equations such that every single student accomplishes conceptual understanding and internalizes the actual scientific knowledge (Retnawati et al., 2018; Zhang et al., 2018). Therefore, scientists resolve the natural phenomena by using tools such as graphs, charts, diagrams and eventually reach to mathematical equations to represent definite physical laws or principles (Brewe \& Sawtelle, 2018).

Electromagnetism is a branch of physics that combines the interactions of electricity and magnetism. The relationship between these two fields in physics is fundamentally connected since 
the activities of one produces the other and vice versa. Electromagnetic interactions play a very important role in explaining the natural world and this interaction is the bases of most modern day technology (Guisasola et al., 2008). Numerous applications of the principles in this aspect of physics is found in industry, offices and home appliances. One could not imagine how life would be without all these appliances and how industries would run without electricity and electric motors. This is the reason why science and physics curriculum developers in all nations of the world include electromagnetism as a core concept in all school and physics curriculum right from Basic that is elementary level to the tertiary level.

For the advantages of electromagnetism to be fully harnessed, the learners should have good understanding of electromagnetic concepts to the point of being able to apply the knowledge, otherwise students will not be able to apply the knowledge (Furió \& Guisasola, 1998; Galili, 1995; Maloney et al., 2001). Guisasola et al. (2008) gave two reasons for the need for good understanding of the field. Firstly, electricity and magnetism is seen as central topics in the science/physics curriculum at any teaching level. Secondly, the concepts and models involving in electromagnetism are particularly problematic. Due to this problematic nature, they recommended the use of models and analogies to teach these concepts because they cannot be observed directly, but only the consequences are evident.

This problematic nature of electromagnetism is reported widely in literature. (Thomas et al., 1995) reported that most students see electromagnetism as abstract and difficult. Electromagnetism is also very wide in content coverage and application. Students learning electromagnetism have to grapple with understanding the principles of electricity and that of magnetism separately so to say and then see how the two phenomena work together. Looking at the reasons that could make this aspect of physics look abstract and difficult to students, it could be because these concepts cannot be observed directly, but only their consequences are evident, as Guisasola et al. (2008) and Constantinou et al. (2008) reported that electromagnetism phenomena are mostly outside the range of students' experiences. Also, since the students are faced with the challenge of understanding principles in electricity and that of magnetism and then the interaction between the two, there is inherent tendency of confusion if those principles are not well understood when taught separately.

The method used by the teacher to teach electromagnetism is another important factor to consider. If the usual conventional method of teaching which has been reported to be popularly used in science classes in Nigeria (Akinsola, 1994; Ireogbu, 1998; Ukoh, 2012) is used, students are likely going to be memorizing the concepts, so that they can pass their examination without actual understanding. Dieck (1997); and Rivard \& Straw (2000); noted that Physics education goals cannot be achieved by conventional science teaching but that most Physics lectures generally are teachercentered and theoretical. Lectures done this way make learning monotonous, impractical and memory dependent (Ireogbu, 1998). Guisasola et al. (2008) also sharing this view and reported that in the traditional electromagnetism teaching sequences at High School (16-18 year old students) and Introductory Physics Courses at university, the usual approach involves rapid introduction of new concepts, models and ways of reasoning, and most time is spent solving different types of exercises. And that conventional teaching enhances abilities to complete only algorithmic problems without students having sufficient time to think about the interaction model behind abstract concepts such as field, flux, potential difference, electromotive force or magnetic induction which only appear related to the formulas.

The reason for this problem is that the method of teaching of physics does not match with the nature of physics and the way students learn. Most physics teacher in Nigeria teach physics verbally without instructional materials to support students learning. Therefore, a majority of the students who learned physics concepts and principles by this conventional teaching method depend on teachers' note as the main source of information and they try to read and memorize them and apply physical rules and definitions without fully understanding the underlying concepts (Erdemir, 2009). This opinion is supported by studies done by (Adesoji, 2008; Redish, 2006; Siam \& Abdo, 2020). Dori et al. (2003) reported that science educators are faced with a challenge of developing and implementing technology-rich learning materials and environment, especially at higher education. 
Also, Sağlam and Millar (2006) observed that although electromagnetism is an important component of upper secondary school physics syllabuses in many countries, there has been relatively little research on students' understanding of the topic and method of teaching that could facilitate easy and meaningful learning therefore this study sort to determine the effect of Interactive-Invention instructional strategy (with students working in group and working individually) on students learning outcome in electromagnetism.

Engaging students with hands-on, eyes-on and mind-on activities gives learners concrete and real-life learning experiences which activate multi-senses for learning thereby addressing different learning styles of the students (Stickel, 2014; Ukoh, 2020) and reducing the abstract nature of the concept. Also, giving students' opportunity for active learning which enhances conceptual and analytical understanding of the concept taught because it gives them opportunity to think and decreases failure rates in the subject. It is also evident that giving opportunity to students to use the knowledge learnt immediately as they are answering the guiding questions in the worksheet, helps them clarify what is not clear to them. Using the learnt knowledge immediately enhances meaningful learning and retention of knowledge.

An engaging and active learning situation is provided by the interactive-invention instructional strategy used in this study which was first used by Ukoh (2012) to teach pre-service teachers some topics in electromagnetism (ferromagnetism, electromagnet, force effect on current carrying conductor in a magnetic field and electromagnetic induction) and was found to be adequately engaging for students in the process of learning. Ogunbowale (2014) used this strategy to teach some concepts in biology to senior secondary school students and reported improved achievement in the subject. Also, Ukoh and Onifade (2020) used it to teach concepts of light, sound and the human eye to secondary school students and reported learning gains with Interactive-Invention instructional strategy than the conventional lecture method. This strategy provides students with, and emphasises rich and effective in-class interacts with their teacher, peers and learning materials and in the process, 'invent' the knowledge they are expected to learn. The teacher acts as a guide in the process of learning by providing prompts and clarifying grey areas as the students manipulate the learning kits and make observations. Students also work with the worksheets in recording their observations and answering the questions. Students were also free to clarify issues from classmates whenever the need arises enforcing collaborative learning.

This method was found to improve students' academic engagement time as they were actively involved in the learning process and hence, their achievement was improved. Science process skills of the students were also increased. Science process skills are skills acquired by students when they are involved in lab work and are used in science inquiry. In this study, students were involved in experimenting with the instrument provided, making manipulations, observing, recording, inferring and making conclusions based on their experimental results.

The ability of the teacher to create a collaborative and supportive learning environment enhanced social interaction and learning. The emphasis on hands-on-activities provides the needed scaffolds as students' support to gain the desired knowledge. As Roosevelt (2008) explained that based on Vygotskian perspective, education is to keep learners in their own ZPDs as often as possible by giving them interesting and culturally meaningful learning and problem-solving tasks that are slightly more difficult than what they do alone. By experiencing it, they will need to work together either with another, more competent peer or with a teacher or adult to finish the task. This was what happened during the experiment where the students followed the procedure by manipulating the equipment, making observations, reporting and drawing inferences. After completing the task jointly, the learner will likely be able to complete the same task individually in the future, and through that process, the learner's ZPD for that particular task will have been raised and learning will be enhanced.

Students' poor performance in electromagnetism is a concern to stakeholders in the subject. Secondary school students' performance in physics has been reported to be poor and electromagnetism is an aspect of physics that has been reported by students to be difficult. Researchers in this area have worked on identifying causes of poor performance and many strategies 
have been developed to improve students' learning in physics but the problem still persist. Therefore, this study determined the effect of teaching electromagnetism using interactive-invention instructional strategy. Attempt was also made to find out what would be working in groups of five and working individually. The research questions to answer in this study are: "What is the experience of students learning physics through Interactive-Invention instructional strategy using the learning kits?" and "Did the students prefer using learning kits to verbal instruction?". Following the questions, the null hypothesis was tested at 0.05 level of significance with $\mathrm{H}_{01}$ : There is no significant main effect of treatment on students' achievement in some concepts in electromagnetism.

\section{Methods}

The research design adopted was pre-test post-test control group quasi experimental design and a total of 125 students participated in the study. Three senior secondary schools were randomly selected from Ibadan North L.G.A. and also randomly assigned to treatment: Treatment group I (44), Treatment group II (39) and control (42). Intact classes were used and the two treatment groups were taught using the interactive-invention instructional strategy with the learning kits but treatment group I participants worked individually while Treatment group II worked in groups of five but control group were taught using the conventional lecture method. Content covered was magnetic field (indication, direction and strength of the field) of an electric current.

Two research instruments were used to gather data for the study and they are: Physics achievement worksheets and in-class interview guide. The Physics Achievement Worksheet contains 3 sections. Section I: background information on the concept of electromagnetism- illustration of the relationship between electricity and magnetism using a coil, battery, electric bulb and two magnetic compasses, the effect of the direction and the strength of the current. Section II: experimental procedure and Section III: worksheets where the students filled as they made observations. Face and content validity was carried out on this instrument and it was found to be valid and reliable. Experimental Group I and II were taught using this Interactive-Invention instructional strategy, the only difference between the two treatment groups was that while participants in group I worked individually, those in group II worked in group of five and the control group were taught using conventional lecture method.

In the set up two small magnetic compasses (a device for detecting magnetic field) are placed one inside and one outside the coil connected to a battery. Before connecting the setup to the battery by the students, they were asked to make observations which they observed no deflection of the magnetic compass needles indicating no magnetic field. When the electric circuit is closed, they were also asked to make observations where they observed both compass needles deflected but in opposite directions, thus demonstrating the presence of magnetic field which could only be due to the electric current. Reversing the connections to the battery caused deflections in the opposite direction and the degree of deflection depends on the strength of the electric current. Students were given background knowledge on the concept and a worksheet containing procedure and questions to guide them in the experiment. So, students worked following the procedure, making observations as they were experimenting and answering the questions. Data collected were analysed using inferential statistics - Analysis of Covariance (ANCOVA) with pretest scores as covariates. Estimated Marginal Means was used to determine the magnitude of mean differences across the treatment groups. Bonferroni post hoc test was used for pairwise comparison.

\section{Results and Discussions}

\section{Testing of Null Hypotheses}

$\mathbf{H}_{\mathbf{0} 1}$ : There is no significant main effect of treatment on students' achievement in selected concepts in electromagnetism.

Table 1 indicates a significant main effect of treatment on students' achievement in selected concepts in electromagnetism $(F(2,124)=72.39 ; p<0.05$, partial $\eta 2=0.56)$. The effect is $56.0 \%$. This indicates that $54.0 \%$ out of the $56.0 \%$ (Adjusted $\mathrm{R} 2=0.68$ ) total variation in students' post- 
achievement in electromagnetism learning in this model is due to the result of the significant main effect of the treatment. Thus, hypothesis 1 was rejected. To explore the magnitude of the significant main effect across treatment groups, the estimated marginal means of the treatment groups were carried out and the result is presented in Table 2.

Table 1. Analysis of Covariance (ANCOVA) of Post-Achievement by Treatment

\begin{tabular}{lrrrrrr}
\hline Source & Type III Sum of Squares & df & Mean Square & \multicolumn{1}{c}{ F } & \multicolumn{1}{c}{ Sig. } & Partial Eta Squared \\
\hline Corrected Model & $1248.878^{\mathrm{a}}$ & 12 & 104.073 & 22.725 & .000 & .709 \\
Intercept & 4497.857 & 1 & 4497.857 & 982.123 & .000 & .898 \\
Interactive-invention & 23.871 & 1 & 23.871 & 5.212 & .024 & .044 \\
Treatment & 663.004 & 2 & 331.502 & 72.385 & $.000^{*}$ & .564 \\
Error & 512.930 & 112 & 4.580 & & & \\
Total & 17599.000 & 125 & & & & \\
Corrected Total & 1761.808 & 124 & & &
\end{tabular}

Table 2. Estimated Marginal Means for Post-achievement by Treatment and Control group

\begin{tabular}{lllll}
\hline \multirow{2}{*}{ Treatment } & \multirow{2}{*}{ Mean } & \multirow{2}{*}{ Std. Error } & \multicolumn{2}{c}{ 95\% Confidence Interval } \\
\cline { 5 - 5 } & & & Lower Bound & Upper Bound \\
\hline Treatment Group 1 (44) & 10.78 & .363 & 10.058 & 11.498 \\
Treatment Group 2 (39) & 15.24 & .461 & 14.322 & 16.149 \\
Control Group (42) & 7.95 & .381 & 7.195 & 8.706 \\
\hline
\end{tabular}

Table 2 indicates that students in Treatment Group 2 had the highest adjusted post-achievement mean score in the experiment in electromagnetism (15.24) among schools in Ibadan North L.G.A., followed by their counterparts in the Treatment Group I (10.78) while those in the Control Group (7.95) had the least adjusted post-achievement mean score in electromagnetism. This order is Treatment Group 2 > Treatment Group 1 > Control Group. In order to determine which of the groups causes this significant main effect, the Bonferroni post-hoc analysis is carried out across the treatment groups and the result is presented in Table 3.

Table 3. Bonferroni Post-hoc Analysis of Post-achievement by Treatment and Control Group

\begin{tabular}{llccc}
\hline \multicolumn{1}{c}{ Treatment } & Mean & Treatment Group 1 & Treatment Group 2 & Control Group \\
\hline Treatment Group 1 & 10.78 & & $*$ & $*$ \\
Treatment Group 2 & 15.24 & $*$ & $*$ & $*$ \\
Control Group & 7.95 & $*$ & $*$ & \\
\hline
\end{tabular}

Table 3 reveals that the post-achievement mean score of students in the Treatment Group 1 is significantly different from their counterparts in Treatment Group 2 and the Control Group. Table 3 also shows that the post-achievement mean score of students in the Treatment Group 2 is significantly different from their counterparts in Treatment Group 1 and the Control Group. This indicates that the significant difference revealed by ANCOVA is not only due to the difference between the treatment groups but also the difference between the treatment groups and the control group as students' post-achievement in electromagnetism.

Research Questions 1 and 2 were answered using the in-class interview. Students in the two treatment groups reported that thy enjoyed the lessons because they were involved in the activities hands-on and they see the physics they were to learn not only being told as their teacher always do verbal teaching without experiment and they wish their teacher will be using this method and related materials to teach them physics. Providing real life learning experiences demystify abstract concepts in physics and help students to be able to conceptualise the knowledge easily without confusion.

\section{Discussion of Findings}

The result of this study revealed a significant main effect of treatment on students' achievement in some electromagnetic concepts. Students working in groups of five exposed to Interactive-invention Instructional Strategy in treatment group II had highest adjusted mean score in their 
post-achievement followed by students working individually in Interactive-invention Instructional Strategy in treatment group I then lastly their counterparts in the Conventional lecture method (control group). The findings showed that Interactive-invention Instructional Strategy is more effective than the conventional lecture method in teaching abstract concepts in physics like electromagnetism whether students are working in groups or working individual however working in group is better than working individually. The findings of (Ogunbowale, 2014; Ukoh, 2012; Ukoh \& Onifade, 2020) agrees with the finding of this study.

The effectiveness of this instructional strategy may be due to the fact that it engages students' in hands-on activities and the outcome of the activities are the knowledge they are expected to learn, making the concepts real and eliminating the abstractness of physics. The strategy also makes provision for students to be involved in practical sessions that illustrated the practical evidence of magnetic field of an electric current to show the connection between electricity and magnetism. As the introduction of electromagnetism without indicating the link between electricity and magnetism may make students think of it as a new topic entirely without seeing it as a continuation and a beginning of the interaction between the two phenomena.

This occurred in an active learning approach setting where learners were active in experimenting and making their observations as they take note of the experimental results. The results were the evidences of the principles underlying in the concept to be learnt. So, students were active in the constructing of the knowledge of the concept they were learning. The students were also made to answer some questions on the worksheet having an opportunity to use the learnt knowledge which enforces meaningful learning and retention.

The result of the control group is not surprising because Ireogbu (1998) and Akinsola (1994) had earlier pointed out the limitations of this method of teaching as always leading to memorisation without understanding of science content but noted that this method is still popular in Nigerian science classes. It is teacher centred and students are not actively involved instead they are made to be passive during the lesson. The teacher in this case depends more on verbal explanations of the content and using theoretical examples. Students are learning in abstraction making misconception eminent more so as the concepts of electromagnetism are abstract, wide and difficult to learn. (Dieck, 1997; Rivard \& Straw, 2000) noted that Physics education goals cannot be achieved by this method of teaching but that it makes the lectures monotonous, impractical and memory dependent Ireogbu (1998) thereby making physics to be considered as the most challenging subject.

Also the result of the study showed that working in groups as in treatment group II gave students higher post-achievement mean score than working individually treatment group I. This finding is supported by the submissions of Center for Teaching Innovation (2020) who believe that educational experiences that are active, social, contextual, engaging and student-owned lead to deeper learning. The success in this (group II) could be attributed to the fact that students were made to work together, make observations and agree on what they observed and reported their observations on the worksheet. If any member of the group made a mistake in the observation another person could correct so they learn from each other. As Vygotsky (1978) believes that social interaction is fundamental to cognitive development and also by Shabani et al. (2010) who explained that the individuals learn best when working together with others during joint collaboration, and that it is through such collaborative endeavors with more skilled persons that learners learn and internalize new concepts, psychological tools, and skills. In this study the teacher serves as the more skilled person and for those that worked in group, other group members could also help out during the process of learning by providing the learning support necessary through the social interaction window provided.

Treatment group II enjoyed what Roosevelt (2008) explained about Vygotskian perspective that education is to keep learners in their own ZPDs as often as possible by giving them interesting and culturally meaningful learning and problem-solving tasks that are slightly more difficult than what they do alone, such that they will need to work together either with another, more competent peer or with a teacher or adult to finish the task and this was what happened during the experiment where the students followed the procedure, manipulating the equipment, making observations, 
reporting and drawing inferences. The idea is that after completing the task jointly, the learner will likely be able to complete the same task individually next time, and through that process, the learner's ZPD for that particular task will have been raised (Roosevelt, 2008) and learning will be enhanced.

This was not the case with group I who worked individually, as anyone making any mistake except he/she noticed it, the mistake stands. However, it was noted during the experiment that Group I students found it much easier to put into practice knowledge learnt than group II because individualised lessons usually lead to mastery learning. Some students in group I made a replica of the learning kit using locally sourced materials. This could have been so because of the inherent challenge of accepting responsibility in group work. It was also noted that class management was more challenging in Group II than in group I as group II was somehow noisy and it took them longer time to finish their work. Group I was quieter and students finished their work to time. The main challenge in working individually was on the cost of having enough materials for all the students. In large classes this could pose a serious challenge.

\section{Conclusion}

Based on the findings of this study it could be concluded that Interactive-Invention instructional strategy improves students learning of electromagnetic concepts and that using this strategy in group works better than students working individually. Students taught with this strategy showed positive attitude to learning of physics as they reported that they enjoyed learning the concepts and wished their teachers could be using strategies like Interactive-Invention instructional strategy where they will have opportunity for hands-on activities to teach all concepts in physics.

The following recommendations were made based on the findings of the study. Physics teachers should use teaching strategies like Interactive-Invention instructional strategy that will engage the students actively during the learning process as students active involvement during lesson enhances meaningful learning. They should organise the students to work in groups as students working in groups were found to do better than those that worked individually. Besides, teachers should endeavour to use learning kits that could illustrate the concepts to be taught so as to demystify abstract concepts in the subject and give students opportunity to manipulate the kits themselves so that they can construct their knowledge with ease. Also, teacher should be discouraged from using teacher centered method of teaching and if they must use should support the students learning with instructional materials.

\section{Reference}

Adesoji, F. A. (2008). Managing students' attitude towards science through problem - solving instructional strategy. The Anthropologist, 10(1), 21-24. https://doi.org/10.1080/09720073.2008.11891024

Akinsola, M. K. (1994). Comparative effects of mastery learning and enhanced mastery learning strategies on students' achievement and self-concept in mathematics. University of Ibadan.

Brewe, E., \& Sawtelle, V. (2018). Modelling instruction for university physics: examining the theory in practice. European Journal of Physics, 39(5), 054001. https://doi.org/10.1088/13616404/aac236

Center for Teaching Innovation. (2020). Collaborative learning. https://teaching.cornell.edu/teaching-resources/active-collaborative-learning/collaborativelearning

Constantinou, C. P., Papaevripidou, M., Lividjis, M., Scholinaki, A., \& Hadjilouca, R. (2008). Teaching and learning about electromagnetism in high school: addressing issues of relevance and epistemic practice. GIREP Conference 2008 Physics Curriculum Design, Development and Validation, 296-302. http://hdl.handle.net/10797/14492

Dieck, A. P. (1997). An effect of a newsletter on children's interest in an attitude toward science 
(Yayımlanmamış yüksek lisans tezi). Arizona State University.

Dori, Y. J., Belcher, J., Bessette, M., Danziger, M., McKinney, A., \& Hult, E. (2003). Technology for active learning. Materials Today, 6(12), 44-49. https://doi.org/10.1016/S1369-7021(03)012252

Erdemir, N. (2009). Determining students' attitude towards physics through problem solving. AsiaPacific Forum on Science Learning and Teaching, 10(2). https://www.eduhk.hk/apfslt/v10_issue2/erdemir/erdemir5.htm

Furió, C., \& Guisasola, J. (1998). Difficulties in learning the concept of electric field. Science Education, 82(4), 511-526. https://doi.org/10.1002/(SICI)1098-237X(199807)82:4<511::AIDSCE6>3.0.CO;2-E

Galili, I. (1995). Mechanics background influences students' conceptions in electromagnetism. International Journal of Science Education, 17(3), 371-387. https://doi.org/10.1080/0950069950170308

Guisasola, J., Michelini, M., Mossenta, A., Testa, I., Viola, R., \& Testa, A. (2008). Teaching electromagnetism: issues and changes. Proceedings of the Girep/EPEC 2007 Conference on Frontiers of Physics Education, 33-37.

Ireogbu, Y. O. (1998). Problem-based learning, numerical ability and gender as determinants achievement in line graphing skills and meaningful learning in energy concepts. University of Ibadan.

Maloney, D. P., O'Kuma, T. L., Hieggelke, C. J., \& Van Heuvelen, A. (2001). Surveying students' conceptual knowledge of electricity and magnetism. American Journal of Physics, 69(S1), S12S23. https://doi.org/10.1119/1.1371296

Ogunbowale, N. B. (2014). Effects of interactive-invention and problem-based instruction strategies on students' attitudes to biology. Journal of Education and Leadership Development, 6(2), 86104.

Redish, E. F. (2006). Problem solving and the use of math in physics courses. http://arxiv.org/abs/physics/0608268

Retnawati, H., Arlinwibowo, J., Wulandari, N., \& Pradani, R. (2018). Teachers' difficulties and strategies in physics teaching and learning that applying mathematics. Journal of Baltic Science Education, 17(1), 120-135. http://www.scientiasocialis.It/jbse/?q=node/643

Rivard, L. P., \& Straw, S. B. (2000). The effect of talk and writing on learning science: An exploratory study. Science Education, 84(5), 566-593. https://doi.org/10.1002/1098237X(200009)84:5<566::AID-SCE2>3.0.CO;2-U

Roosevelt, F. D. (2008). Zone of proximal development. In Encyclopedia of Educational Psychology (pp. 1017-1022). SAGE Publications, Inc. https://doi.org/10.4135/9781412963848.n282

Sağlam, M., \& Millar, R. (2006). Upper high school students' understanding of electromagnetism. International Journal of Science Education, 28(5), 543-566. https://doi.org/10.1080/09500690500339613

Shabani, K., Khatib, M., \& Ebadi, S. (2010). Vygotsky's Zone of proximal development: Instructional implications and teachers' professional development. English Language Teaching, 3(4).

Siam, J., \& Abdo, A. (2020). Effects of inquiry, computer simulation, and cooperation with intergroup competition on electrical engineering students. Research in Science \& Technological Education, 38(4), 439-462. https://doi.org/10.1080/02635143.2019.1643299

Stickel, M. (2014). Teaching electromagnetism with the inverted classroom approach: Student perceptions and lessons learned. 2014 ASEE Annual Conference \& Exposition Proceedings, 24.1160.1-24.1160.15. https://doi.org/10.18260/1-2--23093

Thomas, E. W., Marr, J., \& Walker, N. (1995). Enhancement of intuitive reasoning through precision teaching and simulations. Proceedings Frontiers in Education 1995 25th Annual Conference. 
Engineering Education for the 21st Century, 2, 3c3-10.

Ukoh, E. E. (2012). Effects of problem-based learning and interactive invention instructional strategies on NCE pre-service teachers' achievement in physics concepts and acquisition of science process skills. University of Ibadan.

Ukoh, E. E. (2020). Characteristics of the 21th century learner: A lesson to the physics teacher. In Characteristics of the 21st century learner a lesson to the physics teacher Further thought on Language, Education and the Curriculum Nexus for sustainable development in Nigeria (pp. 387-397). Constellation Books.

Ukoh, E. E., \& Onifade, S. A. (2020). Pre-lesson assignments and formative assessment strategies with interactive invention instruction on low achievers in physics. Momentum: Physics Education Journal, 49-56. https://doi.org/10.21067/mpej.v4i1.3846

Vygotsky, L. S. (1978). Mind in society: The development of higher psychological processes. Mind in Society The Development of Higher Psychological Processes, Mind in So, 159. https://doi.org/10.1007/978-3-540-92784-6

Zhang, C., Wang, H., Liu, Y., \& Jiang, J. (2018). Investigation and the improvement strategy of the inquiry physics experiment teaching in senior high school. American Journal of Physics and Applications, 6(5), 104. https://doi.org/10.11648/j.ajpa.20180605.11 